\title{
CAN ABORTION MORTALITY BE ELIMINATED? WE BELIEVE THE ANSWER IS YES
}

\author{
Roger W. Rochat
}

\begin{abstract}
DOI: http://dx.doi.org/10.7322/jhgd.96828
\end{abstract}
Abortion mortality is an important global public health problem but a relatively neglected area of epidemiologic study. Deaths and complications from unsafe abortion are commonplace in many countries. The World Health Organization (WHO) estimates about 22 million unsafe abortions are performed worldwide each year and about 47,000 women die from unsafe abortion and $99 \%$ of these deaths occur in less developed regions of the world.

Despite widespread global use of abortion it has very limited legal and medical acceptability in Latin America. In part due to the political controversy over the acceptability of abortion as public health intervention, as a medical procedure, and as a woman's right, few public health research studies have been conducted to evaluate interventions to prevent abortion deaths - indeed most countries would be challenged to accurately document the public health problems of abortion. I would like to share three diverse experiences in using epidemiologic tools to help eliminate maternal deaths from abortion.

First, we recently reviewed all of the Center for Disease Control and Prevention's (CDC) Epidemic-Assistance investigations on Maternal and Child Health between 1946 and 2005 and concluded that "the investigations of abortion-related health problems might have had the best-documented impact on public policy and public health ${ }^{1}$. Of 4,484 field investigations 1,969 were judged as potentially related to maternal and child health.

Upon in-depth review of the reports, 1,429 were indeed related to maternal and child health and 25 related to abortion. Yet, investigations of clusters of abortion-related complications led to establishing a nation-wide abortion surveillance system. Then CDC began investigating all reported abortion-related deaths to determine whether the death was attributed to abortion, whether the abortion was spontaneous or induced, and if induced, whether it was a legal or illegal abortion.

Yet another investigation documented the rapid decline in maternal mortality from abortion after decriminalization. And CDC research documented the safety of $D \&$ C for second trimester abortions. Lawyers cited these investigative reports before the U.S. Supreme Court thus contributing to the Court's decision to overthrow state laws making abortion a crime. The final result of these investigative and more in-depth studies and changes in abortion laws and practices have led to evidence that a woman obtaining an abortion early in gestation in the United States has a mortality risk of about 1 in one million.

Second, the internationally-renowned obstetrician-gynecologist, Dr. David Grimes has published an excellent book applying epidemiologic methods to abortion: Every third Woman in America: How Legal Abortion Transformed Our Nation ${ }^{2}$. This book may be downloaded for 99 cents! In language easily readable by a layperson, Dr. Grimes describes three phases of abortion in the United States. Starting with the "bad old days" before 1967 when many women in the United States died from illegal abortions to a transitional time when abortions were legally available on the West and East coastand huge medical tourism led women to California or New York for abortions. He estimates that women spent about $\$ 67$ million in today's dollars travelling to and from these clinics. Following the US Supreme Court decisions, Roe v Wade and in 1973, abortion became legal throughout the US and well accepted in areas which had achieved the second demographic transition ${ }^{3}$.

Moreover, it led to a shift to terminations earlier in pregnancy and to more equitable access to abortion for the poor-indeed the poor are more likely to get an abortion. Today an estimated every third woman in America will have at least one legal abortion. The remainder of the book applies epidemiologic methods to critically examining abortion hot-button issues: "the collision of politics and science".

The American Public Health Association urges medical and public health schools, residency training programs and midwifery and physician assistant programs to teach courses on abortion, and Drs. Eva Lathrop, Emory Medical School Obstetrician/Gynecologist, AndreeaCreanga (CDC

\footnotetext{
1 Professor and Director of Graduate Studies, Hubert Department of Global Health, Rollins School of Public Health - Emory University, Atlanta, GA - USA

Corresponding author: rrochat@emory.edu
}

Suggested citation: Rochat RW. Can abortion mortality be eliminated?We believe the answer is YES. Journal of Human Growth and Development. 25(1): 125-127

Manuscript submitted Oct 08 2014, accepted for publication Feb 222015. 
epidemiologist) and I have, for the past six years, taught a course on the Global Elimination of Maternal Mortality from Abortion (GEMMA) ${ }^{4}$.

The purpose of the course is to educate public health students on laws, policies, clinical methods and case studies that facilitate preventing abortion deaths and on those barriers that enhance the likelihood of dying from abortion. We use Values Clarification and Attitude Transformation (VCAT) techniques to help students identify their own values and to respect other values 5 . We discuss key ethical issues ${ }^{6}$.

A clinician describes how safe abortions are routinely performed and how to treat complications from unsafe abortion. An epidemiologist challenges the class with techniques to estimate abortion incidence and mortality when illegal and how to monitor legal abortions-and also how to evaluate the public health problems of unintended pregnancy and its consequences, including abortion.

We use case studies, including the countries where abortion restrictions have been lifted, like South Africa, Nepal, Colombia, Uruguay and Mexico City and countries, like Romania and Nicaragua, where establishing restrictions led to a rapid rise in maternal mortality from abortion. We discuss the use of menstrual regulation, medical vacuum aspiration, and medical abortions as increasingly acceptable ways to prevent abortion deaths. We acknowledge that highly effective contraception is one of the most acceptable ways to prevent unintended pregnancy.

We engage students with information and exercises on ethics, human rights, and religion. We compare abortion policies and behaviors associated with followers of different religions - and note the marked variation among followers of the same religion in different countries. The acceptance of abortion in Buddhist Japan ${ }^{7}$ and and Taiwan ${ }^{8}$ is very different from its lack of acceptance in Thailand (page $96)^{2}$. Religion is an important social determinant of health ${ }^{9}$, but in the United States, Roman Catholics have a higher abortion rate than others ${ }^{10}$. In addition to encouraging vigorous class discussion, we require students to give a succinct persuasive elevator speech on a topic related to abortion, such as lack of access to abortion for Native American women ${ }^{11}$ and as a final project, to participate in a debate on abortion policy or to develop a proposed research or surveillance proposal.

In addition, the Rollins School of Public Health has established an endowed fund to support its students conducting summer practicums to facilitate the GEMMA goal. During the summer 2014, $10 \%$ of Rollins public health students conducted GEMMArelated fieldwork in countries in Asia, Latin America and Africa. The fund has helped support students studying the acceptability and challenges of legalized abortion in countries such as Nepal, India, Zambia, Ethiopia, South Africa, Togo, Colombia, Uruguay, and Mexico City ${ }^{12}$ and and the challenge of women's rights where abortion is illegal, such as Nicaragua ${ }^{13}$

The public health problem of death and disability from unsafe abortion is preventable. If all women in the world were able to obtain abortion services as safely as those in the US, the world would have fewer than 100 abortion deaths each year. We welcome professional dialogue and collaborative research to achieve this goal.

\section{REFERENCES}

1. Rochat RW, Heath Jr CW, Chu SY, Marchbanks PA. Maternal and Child Health Epi-Aid Investigations, 1946-2005. Am J Epidemiol. 2011; 174(Suppl .11): S80-88. Doi: http:// dx.doi.org/10.1093/aje/kwr304.

2. Grimes D. Every Third Woman in America: How Legal Abortion Transformed Our Nation. [cited 2014 Jul 11]. Available from: http:// www.lulu.com/spotlight/everythirdwoman

3. Lesthaege R, Neidert L. US Presidential Elections and the Spatial Pattern of the American Second Demographic Transition. Population Development Review. 2009; 35(2): 391-400.

4. Lathrop E, Rochat R. The GEMMA Seminar: agraduate public health course on global elimination of maternal mortality from abortion. Contraception. 2013; 87(1):6-10. Doi: http:// dx.doi.org/10.1016/j.contraception. 2012.08.023.

5. Turner KL, Page KC. Abortion Attitude Transformation: a values clarification toolkit for global audiences. Ipas. Chapel Hill: 2008.

6. Gilbert SF, Tyler AL, Zackin EJ. Bioethics and the new embryology: pringboards for debate. Sinauer Associates; 2005.

7. LaFleur WR. Liquid Life: abortion and Buddhism in Japan. Princeton: University Press; 1992.

8. Moskowitz ML.The Haunting Fetus: abortion, sexuality, and the Spirit World in Taiwan. Honolulu (HI): University of Hawai'i Press; 2001.

9. Chinthakanan O, Rochat RW, Morakote N, Chaovisitseree S. The Hidden Problem of Illegal Abortions in Thailand. Chiang Mai Med J. 2014; 53(4): 187-91.

10. Idler EL. Religion as a Social Determinant of Public Health. Oxford University Press; 2014. 
11. Arnold SB. Reproductive rights denied: the hyde Amendment and access to abortion for native american women using indian health service facilities. Am J Public Health. 2014; 104(10): 1892-3. Doi: http://dx.doi.org/10.2105/ AJPH.2014.302084.

12. Olavarrieta CD, Garcia SG, Arangure A, Cravioto V, Villalobos A, AbiSamra R, et al. Women's experiences of and perspectives on abortion at public facilities in Mexico City three years following decriminalization. Int J Gynaecol Obstet. 2012; 118(sup 1): S15-S20. Doi: http:/ /dx.doi.org/10.1016/j.ijgo.2012.05.005119.

13. Luffy SM, Evans DP, Rochat RW. 13. Luffy SM, Evans DP, Rochat RW. Siempre me critican: barriers to reproductive health in Ocotal, Nicaragua. Am J Public Health. 2015; in press. 